\title{
Clinical Outcome of Acute Coronary Syndrome Patients with Left Main Intervention
}

\author{
Hany H. Ebaid ${ }^{\text {a }}$, Khaled E. Al-Rabbat ${ }^{a}$, Ahmed M.A.Bakry ${ }^{b}$, Mohamed A. Hammad ${ }^{\text {b }}$, Al \\ Shimaa M. Sabry ${ }^{\text {a }}$
}

${ }^{\mathrm{a}}$ Department of Cardiology ,

Faculty of Medicine Benha

University, Egypt.

ABSTRACT
Objective: Acute coronary syndrome (ACS) is associated with adverse

${ }^{\mathrm{b}}$ Department of Cardiology, outcomes and is a common cause of death. Presence of left main (LM) disease

Faculty of Medicine,

Zagazig University, Egypt

in patients with ACS may increase the rate of morbidity and mortality. The

Correspondence to:

purpose of the present study was to compare short-term outcomes as well as

Mohamed A. Hammad, major adverse cardiovascular and cerebrovascular events (MACCE) at 30 days Department of Cardiology, Faculty of Medicine, Zagazig University, Egypt in ACS patients with LM disease treated percutaneously or surgically as compared to those with non-LM disease treated percutaneously. Methods: This is a prospective cross-sectional multicenter study carried out on 100 patients with ACS: Group (I): 50 patients with LM disease, Group (II): 50 patients

\section{Email:} without LM disease. The LM group was treated percutaneously or surgically muhammadhanybehary@gm ail.com and the non-LM group was treated percutaneously. The primary end point is the thirty-day incidence of MACCE. Results: Patients with LM disease who Received: 2 May 2021 were treated with percutaneous coronary intervention $(\mathrm{PCI})$ had more frequent Accepted: 14 August 2021 repeat revascularization than those with $\mathrm{LM}$ disease who were treated with coronary artery bypass graft $(\mathrm{CABG})(\mathrm{P}=0.022)$. However, there was no significant statistical difference between LM patients who were treated with PCI and those who were treated with CABG regarding all other 30 days outcomes $(\mathrm{P}>0.05)$. Conclusion: Coronary revascularization of patients with LM disease in the acute setting provided similar outcomes in 30 days when compared to those without LM involvement. ACS patients with LM disease treated with PCI have similar 30 days outcomes in comparison with CABG. However, repeat revascularization was significantly more frequent in LM patients treated with PCI.

KEY WORDS: major adverse cardiovascular, acute coronary syndrome, left main, percutaneous coronary intervention, coronary artery bypass graft. 


\section{Introduction}

Acute coronary syndrome (ACS) patients vary in terms of clinical appearance and the probability of death or non-fatal ischemic accidents in the short and long term ${ }^{[1]}$. About $6 \%$ of ACS patients who undergo coronary angiography have obstructive left main (LM) coronary artery disease, which provides $75-100 \%$ of the left ventricular myocardium. As a result, a severe LM stenosis may result in life-threatening complications ${ }^{[2]}$.

Since patients with obstructive LM coronary artery disease have a greater chance of mortality and morbidity, coronary artery bypass graft (CABG) surgery has been regarded the standard of care for revascularization. There has been significant biomedical advances in the procedure of percutaneous coronary intervention (PCI) for the treatment of obstructive LM coronary artery disease over the last 20 years, including advancements in stent technologies, procedural procedures, and refinement [3] [4]. Several randomised controlled trials (RCTs) evaluating the possible therapeutic role of PCI as an alternative to regular $\mathrm{CABG}$ have shown that stenting achieves comparable rates of mortality and hard clinical endpoints, as well as a lower risk of stroke, though the rate of repeat revascularization is higher [5] [6].

There is scanty recent research in this field, so the aim of this study was to compare short-term outcomes as well as major adverse cardiovascular and cerebrovascular events (MACCE) at 30 days in ACS patients with LM disease treated percutaneously or surgically as compared to those with nonLM disease treated percutaneously.

\section{Methods}

\section{Study design \& patient selection}

This is a prospective cross-sectional multicenter study carried out on patients with ACS attending to Benha University hospital and Zagazig General hospital from October 2018 to June 2020. The study included 100 ACS patients, divided into 2 groups according to the presence of LM disease: Group (I): 50 patients with LM disease, Group (II): 50 patients without LM disease. ACS patients were diagnosed by presence of typical chest pain $\geq 20$ minute, electrocardiogram (ECG) finding as (ST segment deviation $>1 \mathrm{~mm}$, inverted $\mathrm{T}$ wave, 
hyper acute $\mathrm{T}$ wave), cardiac enzymes and troponin elevation ${ }^{[7]}$. Inclusion criteria comprised patients of both genders, aged $\geq 18$ years, referred for coronary angiography within 5 days after pain onset with a main diagnosis of ST-elevation myocardial infarction (STEMI), non-ST elevation myocardial infarction (NSTEMI), or unstable angina (UA). Exclusion criteria were defined as refusal to participate in the study or the presence of other significant heart disease (significant valvular dysfunction, cardiomyopathy, or pericardial disease) or non-cardiac disease that limits life expectancy. This study was approved by Benha Medical Institutional Review board (IRB) at Benha University and an informed consent was obtained from all patients.

\section{Clinical and laboratory assessment}

Patients were subjected to complete history taking including: age, sex and risk factors (hyperlipidemia, hypertension, diabetes mellitus, smoking and family history of coronary artery disease). Physical examination including: heart rate, blood pressure, body mass index (BMI), chest and cardiac examination and Killip class at presentation ${ }^{[8]}$. Cardiac creatine kinase MB, troponin I, random blood sugar, serum creatinine, serum $\mathrm{Na}$ and $\mathrm{K}$ were all done.

\section{2-Lead Electrocardiogram:}

Twelve-lead electrocardiogram was recorded to document absence or presence of ECG findings as (ST segment depression $>1 \mathrm{~mm}$, inverted $\mathrm{T}$ wave) in non STE-ACS patients and to diagnose STEMI patients by the presence of new ST segment elevation at J-point in $\geq 2$ contiguous leads of $\geq 2 \mathrm{~mm}$ in leads $\mathrm{V} 1, \mathrm{~V} 2$ or $\mathrm{V} 3$ and $\geq 1 \mathrm{~mm}$ in other leads ${ }^{[9]}$.

\section{Echocardiography:}

Echocardiography was done in the left lateral decubitus using the commercially available systems (Epiq 7, Philips ultrasound \& Vivid S6, GE ultrasound, Horten, Norway). Images were obtained with a simultaneous ECG signal. Recordings and calculations of different parameters were performed according to the recommendations of the American Society of Echocardiography (ASE) ${ }^{[10]}$.

\section{Coronary angiography}

Invasive coronary angiography was done during hospital stay either immediately on admission in STEMI patients and non STEACS patients with unstable hemodynamics caused by ischemic attacks and in whom ischemic attacks cannot be controlled by intensive drug treatment or within 5 days in stable patients. The SYNTAX score was 
calculated to assess the anatomical complexity of coronary artery disease (CAD) and the long-term mortality and morbidity after PCI. The patients were classified according to SYNTAX score severity into: Low SYNTAX score $(0-22)$, intermediate SYNTAX score $(23$ - 32) and high SYNTAX score $(\geq 33)^{[11]}$.

\section{Myocardial revascularization}

The LM group was treated percutaneously or surgically and the non-LM group was treated percutaneously according to the 2018 European Society of Cardiology (ESC) guidelines ${ }^{[12]}$. The study end point was thirty-day incidence of MACCE defined as the composite of cardiac death, clinically indicated revascularization, transient ischemic attack (TIA), stroke, or myocardial infarction at 30 days.

\section{Statistical analysis}

All data were collected, statistically analyzed using statistical package for the social sciences (SPSS) program version 20 (SPSS, Chicago, IL, USA). Continuous variables were expressed as mean and standard deviation, while categorical variables were expressed as numbers and percentages. Independent samples Student's t-test was used to compare between two groups of normally distributed variables.
While, Mann Whitney U test was used for non-normally distributed variables. Percent of categorical variables were compared using Chi-square test or Fisher's exact test when appropriate. All tests were two-sided. $\mathrm{P}$ value $<0.05$ was considered statistically significant (S), and $p$ value $\geq 0.05$ was considered statistically non-significant (NS).

\section{Results}

Demographic, clinical data and echocardiography among LM and non-LM groups:

Baseline demographic and clinical data are presented in (table 1). Patients with LM disease were older $(63.54 \pm 6.11$ vs. $54.60 \pm$ 9.23 years, $\mathrm{P}=0.006$ ). However, there was no significant statistical difference between LM and non-LM groups regarding gender $(\mathrm{P}=0.34)$. In the present study, there was no significant statistical difference between LM and non-LM groups regarding HTN, DM, dyslipidemia, history of $\mathrm{CAD}$ and prior stroke $(\mathrm{P}=0.86,0.62,0.59,0.09$ and 1$)$ respectively. In this study, there was no significant statistical difference in KILLIP class between LM and non-LM groups $(\mathrm{P}=0.62)$.

In the current study, LVEDV was significantly larger in non-LM group $(\mathrm{P}=0.013)$. While, LVESV was significantly 
larger in LM group $(\mathrm{P}=0.008)$. $\mathrm{EF}$ was significantly lower in LM group $(\mathrm{P}<0.001)$. While, WMSI was significantly higher in LM disease group $(\mathrm{P}<0.001)$. A wave velocity was significantly higher in LM disease group $(\mathrm{P}=0.039)$. There was no significant statistical difference between the two groups regarding $\mathrm{E}$ wave velocity $(\mathrm{P}=0.468)$. $\mathrm{S}$ wave velocity was significantly lower in LM disease group $(\mathrm{P}=0.003)$. There was no significant statistical difference between the two groups regarding $\mathrm{E}^{\prime}$ wave velocity $(\mathrm{P}=0.07)$ and $\mathrm{E} / \mathrm{E}^{\prime}$ ratio $(\mathrm{P}=0.08)$.

\section{Coronary angiography and 30 days} outcomes among LM group versus non-LM group:

In the present study STEMI presentation was significantly more prevalent in non-LM group $\quad(\mathrm{P}=0.001) . \quad$ While, NSTEMI presentation was significantly more prevalent in LM group $(\mathrm{P}=0.028)$. The presence of single vessel disease was significantly more prevalent in non-LM group (26 patients " $52 \%$ " vs. 2 patients "4\%", $\mathrm{P}<0.001)$.

While, presence of three vessel disease was significantly more prevalent in LM group (35 patients " $70 \% "$ vs. 12 patients " $24 \%$ ", $\mathrm{P}<0.001)$. There was no significant statistical difference between the two groups regarding the presence of double vessel disease (13 patients "26\%" vs. 12 patients " $24 \% ", \mathrm{P}=0.9$ ) as shown in figure (1).

There was no significant difference between both groups regarding repeat revascularization (5 patients " $10 \%$ " vs. 6 patients " $12 \% ", \mathrm{P}=0.418)$, reinfarction (2 patients " $4 \%$ " vs. 3 patients " $6 \%$ ", $\mathrm{P}=0.821$ ), arrythmia ( 8 patients " $16 \%$ " vs. 6 patients " $12 \% ", \quad \mathrm{P}=0.612)$, bleeding (3 patients " $6 \%$ " vs. 3 patients " $6 \%$ ", $\mathrm{P}=1.00)$, stroke ( 2 patients " $4 \%$ " vs. 2 patient " $4 \%$ ", $\mathrm{P}=1.00$ ) and death (6 patients " $12 \%$ " vs. 4 patients " $8 \%$ ", $\mathrm{P}=0.523$ ) as shown in figure (2).

Demographic, clinical data and echocardiography among LM disease patients (PCI subgroup versus CABG subgroup):

There was no significant statistical difference between the two subgroups regarding age $(\mathrm{P}=0.271)$ and gender $(\mathrm{P}=0$. 0.323). PCI subgroup included 16 male patients (76.19\%) and 5 female patients (23.81\%). While, CABG subgroup included 17 male patients $(58.62 \%)$ and 12 female patients (41.38\%) (table 2). In the present study, there was no significant statistical difference between PCI and CABG subgroups regarding HTN, DM, 
dyslipidemia, history of $\mathrm{CAD}$ and prior stroke $(\mathrm{P}=0.845,0.634,0.206,0.352$ and 1$)$ respectively. In this study, there was no significant statistical difference in KILLIP class between PCI and CABG subgroups $(\mathrm{P}=0.956)$. In the present study, LVESV was significantly larger in PCI subgroup $(\mathrm{P}=0.019)$. While, EF was significantly lower in PCI subgroup $(\mathrm{P}=0.001)$.

There was no significant statistical difference between the two subgroups regarding $\mathrm{LVEDV}$ and WMSI $(\mathrm{P}=0.354$ and $\mathrm{P}=0.189)$. E wave velocity was significantly higher in PCI subgroup $(\mathrm{P}<0.001)$. There was no significant statistical difference between the two subgroups regarding A wave velocity $(\mathrm{P}=0.917) . \mathrm{E} / \mathrm{E}^{\prime}$ ratio was significantly higher in PCI subgroup $(\mathrm{P}<0.001)$. There was no significant statistical difference between the two subgroups regarding $E^{\prime}$ wave velocity and $S$ wave velocity $(\mathrm{P}=0.474$ and $\mathrm{P}=0.292)$.
Coronary angiography and 30 days outcomes of LM disease patients (PCI subgroup versus CABG subgroup):

In the present study, STEMI presentation was significantly more prevalent in PCI subgroup (5 patients " $20 \%$ " vs. 0 patient " $0 \%, \mathrm{P}=0.024)$. There was no significant statistical difference between the two subgroups regarding NSTEMI and UA presentation. The presence of three vessel disease was significantly more prevalent in CABG subgroup (25 patients " $86 \%$ " vs. 10 patients " $50 \%$ ", $\mathrm{P}=0.023)$. There was no significant statistical difference between the two subgroups regarding the presence of single vessel disease and double vessel disease as shown in figure (3).

Repeat revascularization was significantly more frequent in PCI subgroup (5 patients " $20 \%$ " vs. 0 patient " $0 \%$ ", $\mathrm{P}=0.022$ ). There was no significant statistical difference between the two subgroups regarding all other 30 days outcomes $(\mathrm{P}>0.05)$ as shown in

figure 
Table (1): Comparison between the two groups regarding demographic and clinical data.

\begin{tabular}{|c|c|c|c|c|}
\hline \multirow[t]{2}{*}{ Items } & \multicolumn{2}{|c|}{ Studied groups } & \multirow[b]{2}{*}{ Test } & \multirow[b]{2}{*}{$\mathbf{P}$} \\
\hline & $\begin{array}{c}\text { Group I (no=50) } \\
(\text { LM disease) }\end{array}$ & $\begin{array}{c}\text { Group II (no=50) } \\
\text { (No LM disease) }\end{array}$ & & \\
\hline \multicolumn{5}{|c|}{ Age } \\
\hline \multicolumn{5}{|l|}{ Mean $\pm S D$} \\
\hline Age per years & $63.54 \pm 6.11$ & $54.60 \pm 9.23$ & $\mathrm{~T}=-2.628$ & $0.006(\mathbf{S})$ \\
\hline \multicolumn{5}{|c|}{ Gender } \\
\hline \multicolumn{5}{|l|}{ No $(\%)$} \\
\hline Males & $38(76 \%)$ & $35(70 \%)$ & $\mathrm{X}^{2}=1.221$ & $0.34(\mathrm{NS})$ \\
\hline Females & $12(24 \%)$ & $15(30 \%)$ & & \\
\hline \multicolumn{5}{|c|}{ Risk factors } \\
\hline \multicolumn{5}{|l|}{ No (\%) } \\
\hline HTN & $24(48 \%)$ & $23(46 \%)$ & $X^{2}=0.041$ & $0.86(\mathrm{NS})$ \\
\hline DM & $31(62 \%)$ & $28(56 \%)$ & $X^{2}=0.371$ & $0.62(\mathrm{NS})$ \\
\hline Dyslipidemia & $22(44 \%)$ & $19(38 \%)$ & $\mathrm{X}^{2}=0.48$ & 0.59 (NS) \\
\hline Smoking & $23(46 \%)$ & $24(48 \%)$ & $X^{2}=0.382$ & $0.89(\mathrm{NS})$ \\
\hline Prior CVA & $2(4 \%)$ & $3(6 \%)$ & $\mathrm{F}$ & $1.0(\mathrm{NS})$ \\
\hline Prior CAD & $34(68 \%)$ & $28(56 \%)$ & $X^{2}=3.281$ & $0.09(\mathrm{NS})$ \\
\hline Family History & $16(32 \%)$ & $12(24 \%)$ & $X^{2}=0.391$ & $0.55(\mathrm{NS})$ \\
\hline \multicolumn{5}{|c|}{ Examination } \\
\hline \multicolumn{5}{|l|}{$M e a n \pm S D$} \\
\hline BMI ( $\bar{K} \mathbf{g} / \mathbf{m} 2)$ & $31.60 \pm 3.49$ & $32.12 \pm 3.19$ & $\mathrm{~T}=0.251$ & $0.82(\mathrm{NS})$ \\
\hline SBP (mmHg) & $124.00 \pm 20.11$ & $128.80 \pm 22.79$ & $\mathrm{~T}=0.877$ & $0.39(\mathrm{NS})$ \\
\hline DBP (mmHg) & $80.24 \pm 17.00$ & $84.52 \pm 13.64$ & $\mathrm{~T}=1.418$ & $0.16(\mathrm{NS})$ \\
\hline Heart rate (Beat/min) & $83.55 \pm 15.23$ & $85.89 \pm 15.77$ & $\mathrm{~T}=0.719$ & $0.51(\mathrm{NS})$ \\
\hline \multicolumn{5}{|l|}{ Killip class } \\
\hline Median (Range) & $1(1-3)$ & $1(1-3)$ & $\mathrm{MW}=1198.1$ & $0.62(\mathrm{NS})$ \\
\hline I & $40(80 \%)$ & $37(74 \%)$ & & \\
\hline II & $8(16 \%)$ & $12(24 \%)$ & & \\
\hline III & $2(4 \%)$ & $1(2 \%)$ & & \\
\hline
\end{tabular}

T: Student's T-test, $\chi^{2}$ : Chi-square test, F: Fisher exact test, MW: Mann-Whitney U test, NS: Non-significant, S: Significant, SD: Standard deviation, LM: Left main, HTN: Hypertension, DM: Diabetes mellites, CVA: Cerebrovascular accident, CAD: Coronary artery disease, BMI: Body mass index, SBP: Systolic blood pressure, DBP: Diastolic blood pressure. 
Benha medical journal, vol. 38, issue 3, 2021

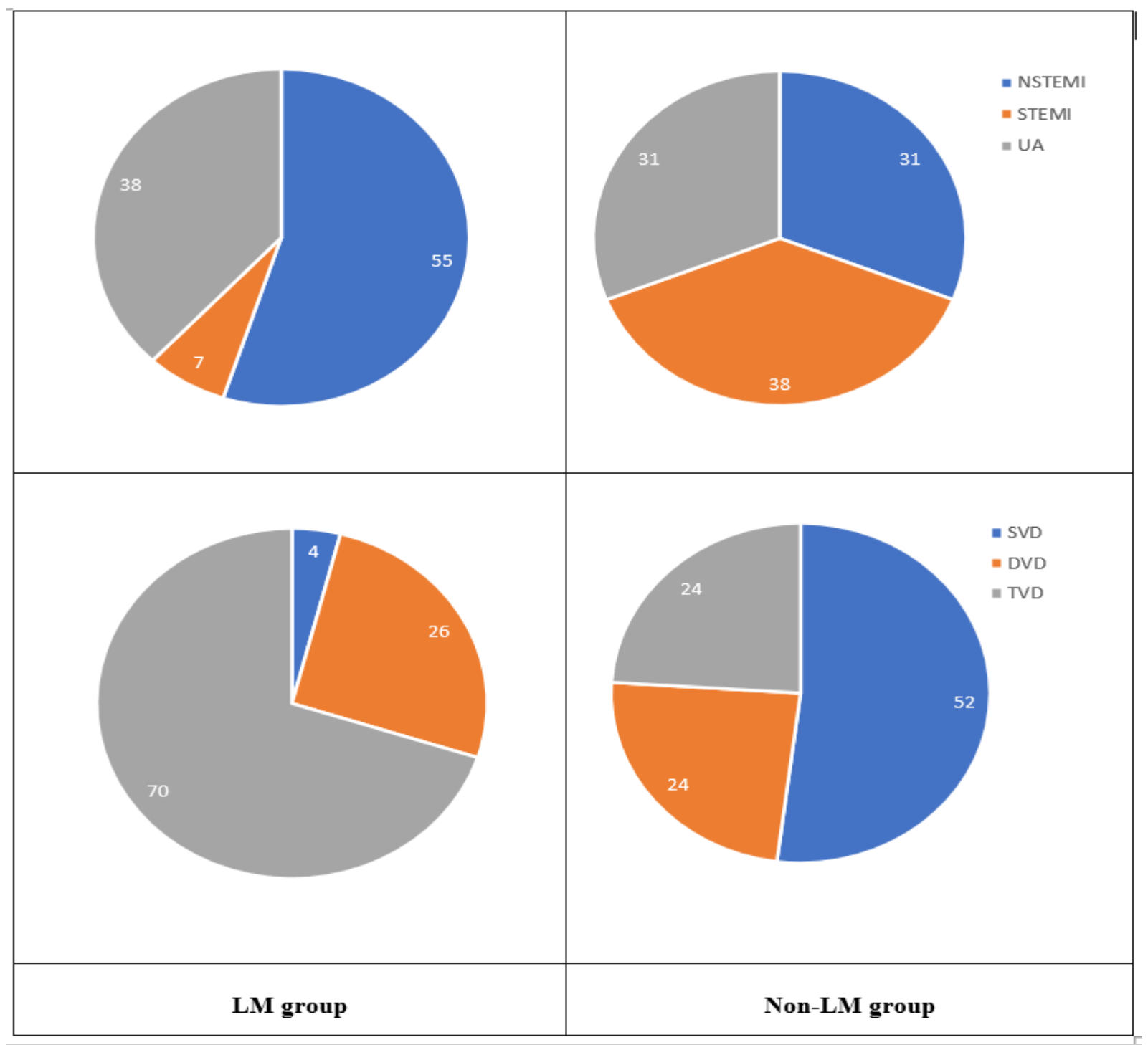

Figure (1): Comparison between LM and Non-LM groups regarding types of acute coronary syndrome and number of vessels affected on coronary angiography. 


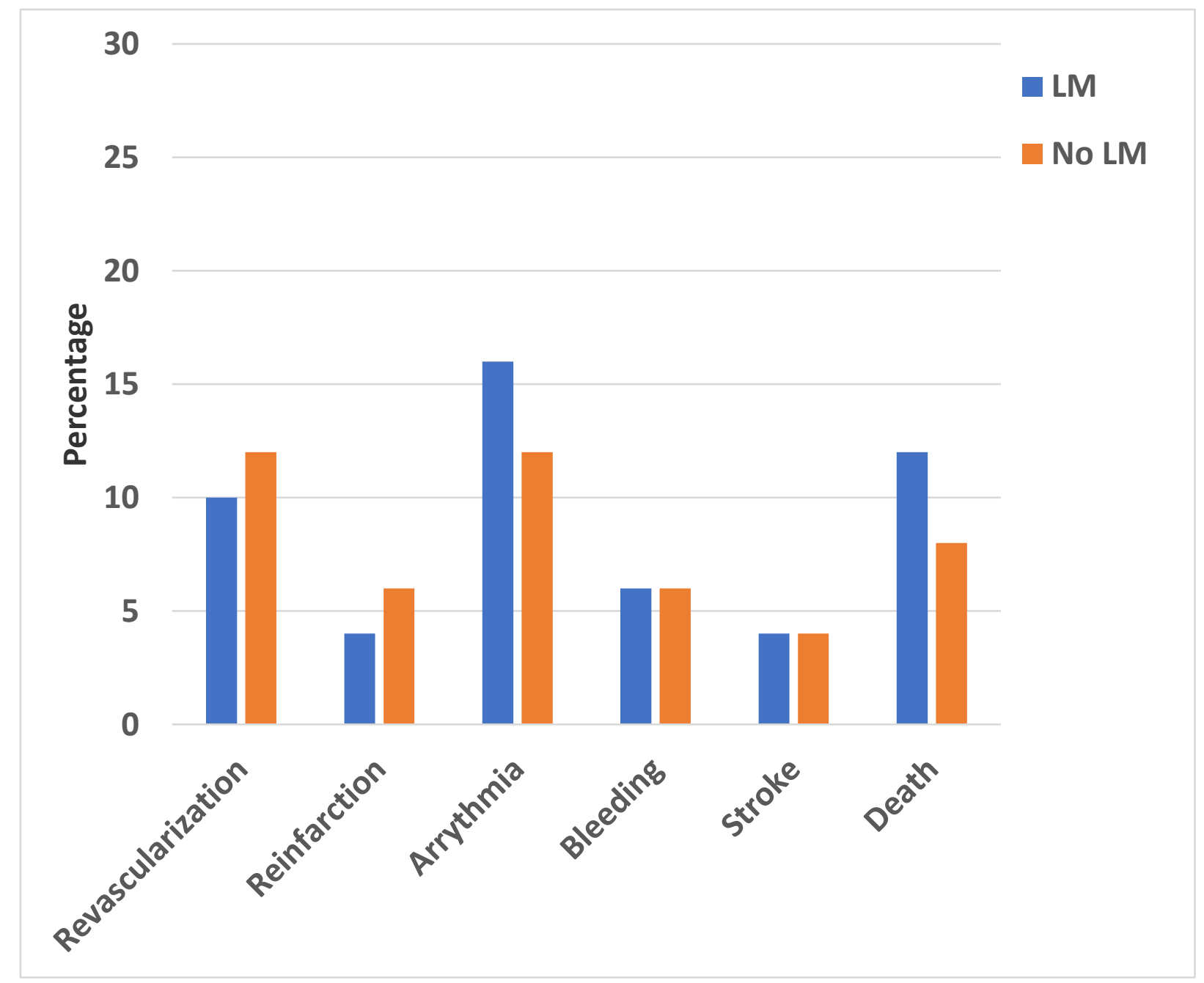

Figure (2): Comparison between the two groups regarding 30 days outcomes. 
Table (2): Comparison between the two subgroups regarding demographic and clinical data.

\begin{tabular}{|c|c|c|c|c|}
\hline \multirow[t]{2}{*}{ Items } & \multicolumn{2}{|c|}{ Studied groups } & \multirow[b]{2}{*}{ Test } & \multirow[b]{2}{*}{$\mathbf{P}$} \\
\hline & $\begin{array}{c}\text { Group IA (no=21) } \\
\text { (PCI subgroup) }\end{array}$ & $\begin{array}{l}\text { Group IB }(\text { no=29) } \\
\text { (CABG subgroup) }\end{array}$ & & \\
\hline \multicolumn{5}{|c|}{ Age } \\
\hline \multicolumn{5}{|l|}{ Mean $\pm S D$} \\
\hline Age per years & $61.45 \pm 6.34$ & $62.78 \pm 5.84$ & $\mathrm{~T}=-1.131$ & $0.271(\mathrm{NS})$ \\
\hline \multicolumn{5}{|c|}{ Gender } \\
\hline \multicolumn{5}{|l|}{ No $(\%)$} \\
\hline Males & $16(76.19 \%)$ & $17(58.62 \%)$ & $\mathrm{X}^{2}=1.512$ & $0.323(\mathrm{NS})$ \\
\hline Females & $5(23.81 \%)$ & $12(41.38 \%)$ & & \\
\hline \multicolumn{5}{|c|}{ Risk factors } \\
\hline \multicolumn{5}{|l|}{ No $(\%)$} \\
\hline HTN & $11(52.38 \%)$ & $12(41.38 \%)$ & $\mathrm{X}^{2}=0.046$ & $0.845(\mathrm{NS})$ \\
\hline DM & $14(66.66 \%)$ & $15(51.72 \%)$ & $\mathrm{X}^{2}=0.311$ & $0.634(\mathrm{NS})$ \\
\hline Dyslipidemia & $10(47.61 \%)$ & $10(34.48 \%)$ & $X^{2}=1.574$ & $0.206(\mathrm{NS})$ \\
\hline Smoking & $8(38.09 \%)$ & $12(41.38 \%)$ & $\mathrm{X}^{2}=2.845$ & $0.102(\mathrm{NS})$ \\
\hline CVA & $1(4.76 \%)$ & $1(3.45 \%)$ & $\mathrm{F}$ & $1.000(\mathrm{NS})$ \\
\hline CAD & $16(76.19 \%)$ & $17(58.62 \%)$ & $X^{2}=0.912$ & $0.352(\mathrm{NS})$ \\
\hline Family History & $8(38.1 \%)$ & $10(34.48 \%)$ & $\mathrm{X}^{2}=0.328$ & $0.603(\mathrm{NS})$ \\
\hline \multicolumn{5}{|c|}{ Examination } \\
\hline \multicolumn{5}{|l|}{$M e a n \pm S D$} \\
\hline BMI (Kg/m2) & $30.15 \pm 3.22$ & $29.32 \pm 3.29$ & $\mathrm{~T}=1.085$ & $0.297(\mathrm{NS})$ \\
\hline SBP (mmHg) & $127.65 \pm 28.3$ & $123.26 \pm 24.4$ & $\mathrm{~T}=0.821$ & $0.510(\mathrm{NS})$ \\
\hline DBP (mmHg) & $82.55 \pm 18.28$ & $79.33 \pm 15.47$ & $\mathrm{~T}=0.693$ & $0.552(\mathrm{NS})$ \\
\hline Heart rate (Beat/min) & $87.38 \pm 18.77$ & $85.43 \pm 16.63$ & $\mathrm{~T}=0.299$ & $0.811(\mathrm{NS})$ \\
\hline \multicolumn{5}{|l|}{ Killip class } \\
\hline Median (Range) & $1(1-3)$ & $1(1-3)$ & -301 & C) \\
\hline \multicolumn{5}{|l|}{ No $(\%)$} \\
\hline I & $17(81 \%)$ & $23(79 \%)$ & & \\
\hline II & $3(14 \%)$ & $4(14 \%)$ & & \\
\hline III & $1(5 \%)$ & $2(7 \%)$ & & \\
\hline
\end{tabular}

T: Student's T-test, $\chi^{2}$ : Chi-square test, F: Fisher exact test, MW: Mann-Whitney U test, NS: Non-significant, SD: Standard deviation, PCI: Percutaneous coronary intervention, CABG: Coronary artery bypass graft, HTN: Hypertension, DM: Diabetes mellites, CVA: Cerebrovascular accident, CAD: Coronary artery disease, BMI: Body mass index, SBP: Systolic blood pressure, DBP: Diastolic blood pressure. 


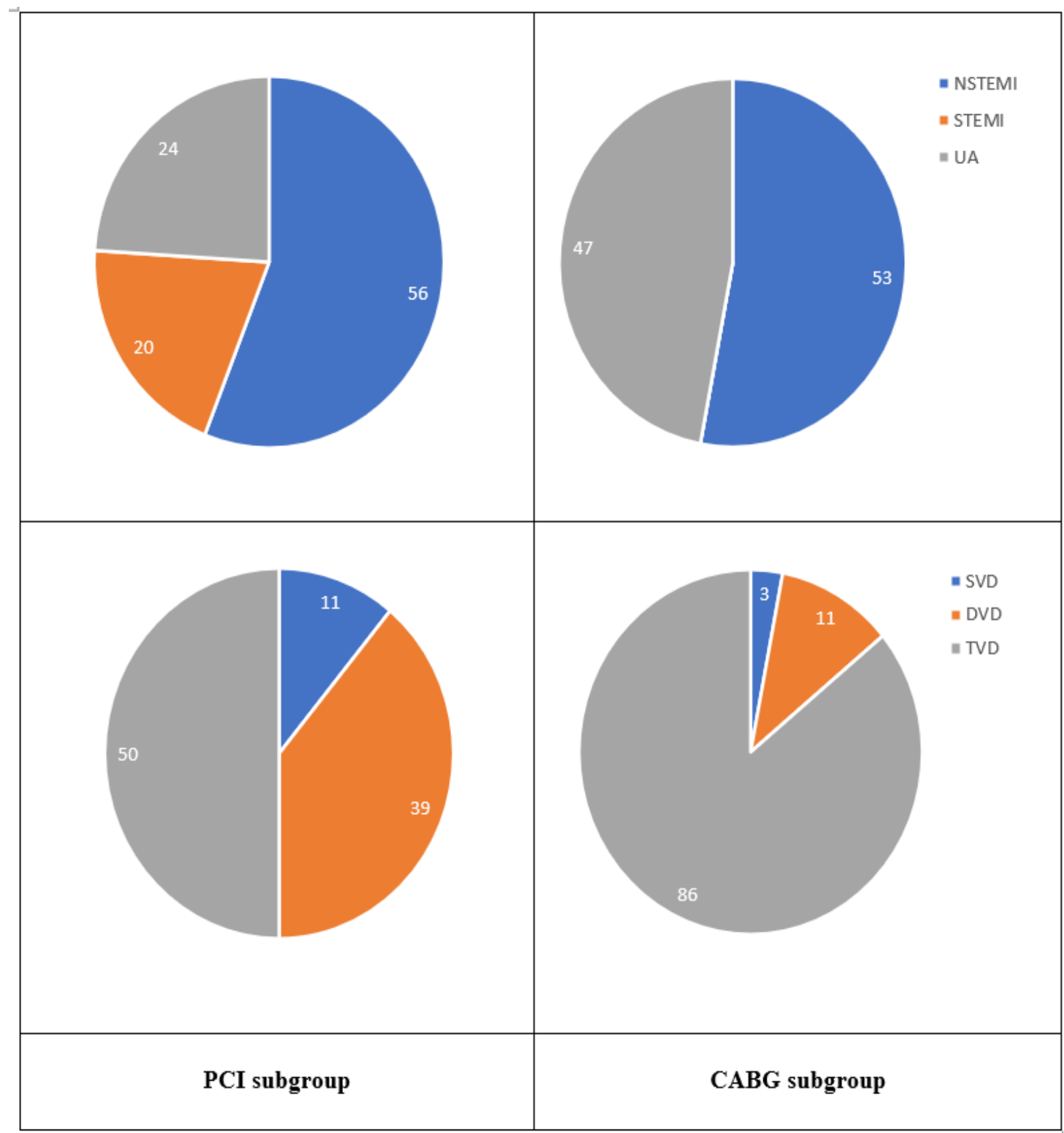

Figure (3): Comparison among LM diseases patients (PCI subgroup and CABG subgroup) regarding types of acute coronary syndromes and number of vessels affected on coronary angiography. 


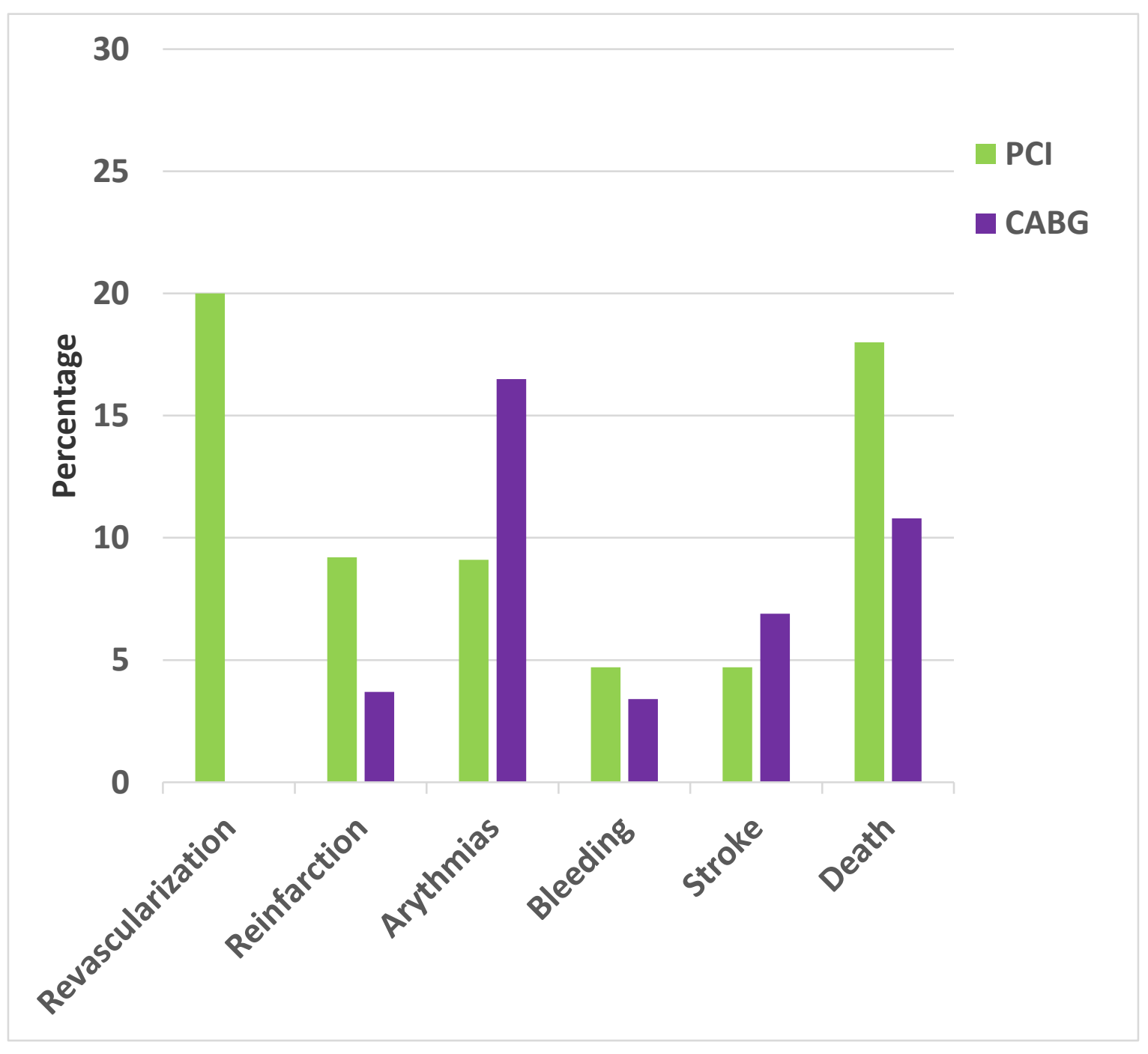

Figure (4): Comparison between the two subgroups regarding 30 days outcomes.

\section{Discussion}

About five percent of patients receiving coronary angiography have significant left major coronary artery disease ${ }^{[13]}$. Patients who have a left primary coronary artery stenosis revascularized are at a high risk of having a heart attack or stroke. For LM stenosis, CABG was thought to be the gold standard ${ }^{[14]}$. However, as stent technology has improved and operator expertise has grown, the number of percutaneous coronary procedures to treat LM stenosis has increased ${ }^{[15]}$. The purpose of the present 
study was also to compare short-term outcomes as well as MACCE at 30 days in acute coronary syndrome patients with LM disease that were treated percutaneously or surgically as compared to those with nonLM disease that were treated percutaneously in a group of Egyptian patients enrolled from two centers (double-centered study), it included 100 patients with acute coronary syndrome, divided into 2 groups according to the presence of LM disease: Group (I): 50 patients with ACS and LM disease and Group (II): 50 patients with ACS without LM disease.

In this study, there was no significant difference between both groups regarding 30 days outcomes including repeat revascularization, re-infarction, arrythmia, bleeding, stroke and death $(\mathrm{P}=0.428,0.835$, $0.578,1.00,1.00$ and 0.689$)$ respectively. This was in agreement with Obeid et al. who reported that there was no significant statistical difference between LM and nonLM groups regarding 30 days net adverse clinical events including death, myocardial infarction, cerebrovascular accident and bleeding $(\mathrm{P}=0.1)^{[16]}$.

In this study, patients with LM disease were divided into 2 subgroups according to the procedure, the first subgroup underwent
PCI and the second one underwent CABG. There was no significant statistical difference between the two subgroups regarding age $(\mathrm{P}=0.271)$ and gender $(\mathrm{P}=0.323)$. There was also no significant statistical difference between the PCI and CABG subgroups regarding hypertension, diabetes, dyslipidemia, smoking, history of previous cerebrovascular accident, history of previous CAD, family history of CAD and BMI (0.845，0.634，0.206，0.102，1.000, $0.352,0.603$ and 0.297$)$ respectively. This was in agreement with Buszman et al. who reported that there was no significant statistical difference between the two groups regarding age, gender, hypertension, diabetes, dyslipidemia and history of previous CAD $(\mathrm{P}=0.69,0.13,0.78,0.80$, 0.78 and 0.60) respectively ${ }^{[17]}$. Similar results are reported by Boudriot et al. who reported that there was no significant statistical difference between the two groups regarding hypertension, diabetes, dyslipidemia, smoking, history of previous cerebrovascular accident, history of previous CAD and BMI $(\mathrm{P}=0.88,0.35,0.89,0.34$, $0.51,0.43$ and 0.31$)$ respectively ${ }^{[18]}$. Also, similar results were reported by Ahn et al. who found that there was no significant statistical difference between the two groups regarding diabetes $(\mathrm{P}=0.66)^{[19]}$. Holm et al. 
also found that there was no significant statistical difference between the two groups regarding age, gender, and $\mathrm{BMI}(\mathrm{P}=0.37$, 0.22 , and 0.45$)$, respectively ${ }^{[20]}$. In the present study, LVESV was significantly larger in PCI subgroup $(\mathrm{P}=0.019)$. While, EF was significantly lower in PCI subgroup $(\mathrm{P}=0.001)$. There was no significant statistical difference between the two subgroups regarding LVEDV and WMSI $(\mathrm{P}=0.354$ and $\mathrm{P}=0.189)$. On the contrary, Boudriot et al. found no significant statistical difference between the two groups regarding $\mathrm{EF}(\mathrm{P}=0.86)^{[18]}$. The disagreement between our results and those reported by Boudriot et al. may be due to the different patient presentations and selection. In the present study, $20 \%$ and $56 \%$ of the patients of PCI subgroup had STEMI \& NSTEMI respectively. While, patients with myocardial infarction were excluded in their study ${ }^{[\mathbf{1 8}]}$.

In the current study, there was no significant statistical difference between the two subgroups regarding the presence of single vessel disease and double vessel disease $(\mathrm{P}=0.634$ and 0.11$)$ respectively. However, in our work, three vessel disease was significantly more prevalent in $\mathrm{CABG}$ subgroup $(\mathrm{P}=0.023)$. In the study of Buszman et al. they reported that there was no significant statistical difference between the two groups regarding the presence of single vessel disease, double vessel disease and three vessel disease $(P=0.17,0.32$ and 0.08) respectively ${ }^{[17]}$. This difference regarding three vessel disease can be attributed to the different characteristics of our patients; where in our study patients who underwent $\mathrm{CABG}$ had a higher SYNTAX score $(\mathrm{P}=0.002)$. Current 2018 European Society of Cardiology (ESC) guidelines have adopted SYNTAX score to aid in selection of the appropriate revascularization strategy for LM coronary artery stenosis, and clinical practice in Egypt usually follows these guidelines ${ }^{[12]}$. This was in contrast to Ahn et al. who found no significant statistical difference between the two groups regarding SYNTAX score $(\mathrm{P}=0.49)$ as in their study, done in Asan Medical Centre, Seoul, South Korea, SYNTAX score did not discriminate the more appropriate strategy between treatments ${ }^{[19]}$.

In the current study, repeat revascularization at 30 days was significantly more frequent in PCI subgroup $(\mathrm{P}=0.022)$. This was in contrast with Buszman et al. who found that there was no significant statistical difference between the two groups regarding repeat 
revascularization at 30 days. This discrepancy might be attributed to larger sample volume included in their study ${ }^{[17]}$. Also, results reported by Boudriot et al. showed that PCI was noninferior to $\mathrm{CABG}$ regarding repeat revascularization at 30 days $(\mathrm{P}<0.001)$. This discrepancy might be attributed to larger sample size of their study [18]. This was in agreement with Buszman et al. who found that repeat revascularization at 1 year was significantly more frequent in PCI group $(\mathrm{P}=0.01)^{[17]}$. In our work, there was no significant statistical difference between the two subgroups regarding other 30 days outcomes including reinfarction, arrythmia, bleeding, stroke and death $(\mathrm{P}=0.635,0.715,1.00,1.00$ and 0.597$)$. This was in agreement with Buszman et al. who found that there was no significant statistical difference between the two groups regarding 30 days outcomes including reinfarction, arrythmia, bleeding, stroke and death ${ }^{[17]}$. Also, similar results are reported by Boudriot et al. who found that PCI was noninferior to $\mathrm{CABG}$ regarding reinfarction at 30 days $(\mathrm{P}=0.002)^{[\mathbf{1 8}]}$.

The limitations of our study included the relatively limited number of patients and lack of longer-term follow-up. Moreover, our study was applied on ACS patients only; excluding those with chronic coronary syndromes undergoing coronary revascularization. The choice of treatment strategy, vascular access, type of stent, and concomitant medications in our study might have reflected individual physician's preferences.

Finally, we conclude that coronary revascularization of patients with LM disease in the acute setting provided similar outcomes in 30 days when compared to those without LM involvement. ACS patients with LM disease treated with PCI have similar 30 days outcomes in comparison with CABG. However, repeat revascularization was significantly more frequent in LM patients who where treated with PCI.

\section{References:}

1. Cakar MA, Sahinkus S, Aydin E, Vatan MB, Keser N, Akdemir R, et al. Relation between the GRACE score and severity of atherosclerosis in acute coronary syndrome. Journal of Cardiology 2014; 63(1):24-28.

2. Fajadet $\mathbf{J}$ and Chieffo A. Current management of left main coronary artery disease. Eur Heart J 2012; $33: 36 b-50 b$.

3. Park SJ and Park DW. Percutaneous coronary intervention with stent implantation versus coronary artery bypass surgery for treatment of left main coronary artery disease: is it time to change guidelines? Circ Cardiovasc Interv 2009; 2:59-68.

4. Lee PH, Ahn JM, Chang M, Baek S, Yoon SH, Kang SJ, et al. Left main coronary artery disease: 
secular trends in patient characteristics, treatments, and outcomes. J Am Coll Cardiol 2016; 68:12331246.

5. Park SJ, Kim YH, Park DW, Yun SC, Ahn JM, Song HG, et al. Randomized trial of stents versus bypass surgery for left main coronary artery disease. N Engl J Med 2011; 364:1718-1727.

6. Buszman PE, Buszman PP, Banasiewicz-Szkróbka I, Milewski KP, Żurakowski A, Orlik B, et al. Left main stenting in comparison with surgical revascularization: 10-year outcomes of the (left main coronary artery stenting) LE MANS trial. JACC Cardiovasc Interv 2016; 9(4):318-327.

7. Thygesen, K, Alpert JS, Jaffe AS, Chaitman BR, Bax JJ, Morrow DA, et al. Fourth universal definition of myocardial infarction (2018). Eur Heart J 2019; 40:237-269.

8. Nesković AN, Otasević P, Bojić M and Popović AD. Association of Killip class on admission and left ventricular dilatation after myocardial infarction: a closer look into an old clinical classification. $\mathrm{Am}$ Heart J 1999; 137(2):361-367.

9. Bhave PD, Hoffmayer KS, Armstrong EJ, Garg S, Patel A, MacGregor JS, et al. Predictors of depressed left ventricular function in patients presenting with ST-elevation myocardial infarction. Am $J$ Cardiol 2012; 109(3):327-331.

10. Lang RM, Badano LP, Mor-Avi V, Afilalo J, Armstrong A, Ernande L, et al. Recommendations for cardiac chamber quantification by echocardiography in adults: an update from the American Society of Echocardiography and the European Association of Cardiovascular Imaging. European Heart JournalCardiovascular Imaging 2015; 1:16(3):233-271.

11. Valgimigli M, Serruys PW, Tsuchida K, Vaina S, Morel MA, van den Brand MJ, et al. Cyphering the complexity of coronary artery disease using the syntax score to predict clinical outcome in patients with three-vessel lumen obstruction undergoing percutaneous coronary intervention. Am J Cardiol 2007; 99(8): 1072-1081.
12. Neumann FJ, Sousa-Uva M, Ahlsson A, Alfonso

F, Banning AP, Benedetto U, et al. 2018 ESC/EACTS Guidelines on myocardial revascularization. Eur Heart J 2019; 40:87-165.

13. Huang HW, Brent BN and Shaw RE. Trends in percutaneous versus surgical revascularization of unprotected left main coronary stenosis in the drugeluting stent era: a report from the American College of Cardiology-National Cardiovascular Data Registry (ACC-NCDR). Catheter Cardiovasc Interv 2006; 68:867-872.

14. Yusuf S, Zucker D, Passamani E, Peduzzi P, Takaro T, Fisher LD, et al. Effect of coronary artery bypass graft surgery on survival: overview of 10-year results from randomised trials by the Coronary Artery Bypass Graft Surgery Trialists Collaboration. The lancet 1994; 344:563-570.

15. Meliga E, Garcia-Garcia HM, Valgimigli M, Chieffo A, Biondi-Zoccai G, Maree AO, et al. Longest available clinical outcomes after drugeluting stent implantation for unprotected left main coronary artery disease: the DELFT (Drug Eluting stent for LeFT main) Registry. J Am Coll Cardiol 2008; 51:2212-2219.

16. Obeid S, Yousif N, Schelldorfer A, Shahin M, Räber L, Gencer B, et al. Short-Term Outcome After Left Main Interventions in Patients Presenting With Acute Coronary Syndrome. J Invasive Cardiol 2018; 30(3):98-104.

17. Buszman PE, Kiesz SR, Bochenek A, PeszekPrzybyla E, Szkrobka I, Debinski M, et al. Acute and late outcomes of unprotected left main stenting in comparison with surgical revascularization. $J \mathrm{Am}$ Coll Cardiol 2008; 51(5):538-545.

18. Boudriot E, Thiele H, Walther T, Liebetrau C, Boeckstegers P, Pohl T, et al. Randomized comparison of percutaneous coronary intervention with sirolimus-eluting stents versus coronary artery bypass grafting in unprotected left main stem stenosis. J Am Coll Cardiol 2011; 57(5):538-545.

19. Ahn JM, Roh JH, Kim YH, Park DW, Yun SC, Lee $\mathrm{PH}$, et al. Randomized trial of stents versus 
bypass surgery for left main coronary artery disease: 5-year outcomes of the PRECOMBAT study. J Am Coll Cardiol 2015; 65(20):2198-2206.

20. Holm NR, Mäkikallio T, Lindsay MM, Spence MS, Erglis A, Menown IB, et al. Percutaneous coronary angioplasty versus coronary artery bypass grafting in the treatment of unprotected left main stenosis: updated 5-year outcomes from the randomised, non-inferiority NOBLE trial. The lancet 2020; 395(10219):191-199.

To cite this article: Hany H. Ebaid, Khaled E. Al-Rabbat, Ahmed M.A.Bakry, Mohamed A. Hammad, Al Shimaa M. Sabry. Clinical Outcome of Acute Coronary Syndrome Patients with Left Main Intervention. BMFJ 2021;38(3): 891- 907. DOI: 10.21608/bmfj.2021.74873.1415 